\title{
Role of habitat complexity in structuring temperate rockpool ichthyofaunas
}

\author{
S. P. Griffiths ${ }^{1,2,3, *}$, A. R. Davis ${ }^{2}$, R. J. West ${ }^{1}$ \\ ${ }^{1}$ Environmental Science, University of Wollongong, Wollongong, New South Wales 2522, Australia \\ ${ }^{2}$ Institute for Conservation Biology, University of Wollongong, Wollongong, New South Wales 2522, Australia \\ ${ }^{3}$ Present address: CSIRO Marine and Atmospheric Research, PO Box 120, Cleveland, Queensland 4163, Australia
}

\begin{abstract}
Habitat complexity in temperate intertidal rockpools was manipulated to assess its effect on fish assemblage structure. We modified the complexity of the substratum within pools by adding or removing loose rocks. The complexity of the water column within pools was modified by the removal of macro-algae and the addition of artificial algae. We applied 5 treatments to 40 pools in 2 locations on the southeast Australian coast: addition of rocks and algae $(+\mathrm{R}+\mathrm{A})$, removal of rocks and algae $(-\mathrm{R}-\mathrm{A})$, removal of rocks but addition of algae $(-\mathrm{R}+\mathrm{A})$, addition of rocks and removal of algae (+R-A), and unmanipulated control pools $(\mathrm{C})$. Changes in algal cover alone had no significant effect on fish assemblages. The total number of individual fishes, species richness, species composition and abundance of the 4 most abundant species only differed in the $-\mathrm{R}-\mathrm{A}$ treatment. There was no change in the length-frequency distributions of the most abundant species after habitat manipulations. The effects of manipulating substratum habitat complexity were investigated further by reversing the treatments in the same pools, i.e. by adding rocks to pools where rock had previously been removed and vice versa. This resulted in a significant increase in species richness and the numbers of individuals in rockpools where substratum heterogeneity had been increased, relative to pools in which it had been decreased. This study revealed that rockpool fishes do not discriminate between the structural complexity within these 2 microhabitats (substratum and water column) so long as some shelter is available. However, substratum complexity may represent the most attractive shelter, since most species are benthic or at least demersal. We speculated that the lack of habitat specificity exhibited by fishes in this study may be due to many rockpool fishes only using rockpools as temporary refugia at low tide.
\end{abstract}

KEY WORDS: Tidepool - Intertidal - Habitat structure - Cover - Recolonisation - Recruitment · Persistence · Artificial Seagrass Units (ASUs)

-Resale or republication not permitted without written consent of the publisher

\section{INTRODUCTION}

The physical structure of habitats within an environment is an important factor that influences the distribution and abundance of individual species, and it may be an important determinant of the structure of a community (Grinnell 1917, Gause 1934, Huffaker 1958). The physical nature of habitat structure, or habitat complexity, can influence the composition of species in the community by providing refugia for prey (Hixon \& Beets 1993, Caley \& St John 1996, Friedlander \& Parrish
1998) and influencing the availability of resources and their rate of acquisition (Safriel \& Ben-Eliahu 1991). Consequently, at the community level, greater structural complexity often results in elevated species richness (Kohn 1967).

Over the past 2 decades there has been considerable interest in the influence of habitat complexity on fish recruitment and the structure of fish assemblages in estuaries (Bell et al. 1985, Bell \& Westoby 1986a,b,c, Bell et al. 1987, Laegdsgaard \& Johnson 2001), coral reefs (Jones \& Syms 1998, Steele 1999) and temperate reefs 
(Angel \& Ojeda 2001, Garcia-Charton \& Perez-Ruzafa 2001). Manipulation experiments in these coastal habitats have shown that higher fish densities and species richness of fish are supported by more physically complex habitats as a result of increased shelter, which makes small fish and new recruits less vulnerable to predation (Bell \& Westoby 1986a, b, Bell et al. 1987).

The intertidal zone can offer a highly structurally complex environment, which may in turn influence fish assemblages (Horn et al. 1999), especially within tidally isolated rockpools. Two main microhabitats are available to fishes within rockpools, and each may differ in their degree of complexity. The substratum of the pool may vary from bare sand, gravel and broken shells, to rocks of various sizes where fish can be partially or completely hidden. Substratum complexity may therefore be important to fishes that spend the vast majority of their time on or near the substratum (Davis 2000). Alternatively, the leaves of aquatic macrophytes, such as seaweeds, create a complex habitat in the water column and can be occupied by midwater or pelagic species in rockpools.

There have been numerous attempts to identify the influence of these 2 habitats on the structure of rockpool fish assemblages using mensurative studies (Marsh et al. 1978, Bennett \& Griffiths 1984). Rockpools containing algal cover have been shown to support higher numbers of species and individuals, particularly clinids (Marsh et al. 1978), and different species composition compared to rockpools with only bare substrata (Bennett \& Griffiths 1984).

Few studies have experimentally tested the importance of rockpool habitats on fish assemblages, and all have concentrated on manipulating substratum cover or 'rugosity' (Cross 1981, Davis 2000, Silberschneider \& Booth 2001). Davis (2000) found that a decrease in substratum cover led to a significant decrease in the numbers of species and individuals. An increase in substratum cover had the opposite effect but was not statistically significant. Apparently, no study has investigated the influence of suspended cover on the structure of intertidal rockpool fish assemblages (but see Cross 1981, Silberschneider \& Booth 2001).

The aim of this study was to investigate the effects of manipulating the complexity of 2 major rockpool microhabitats (the substratum and the water column) on the structure of rockpool fish assemblages and size composition of common species, over ecologically realistic time scales. It was expected that the number of species and individuals would increase with increasing habitat complexity and decrease with decreasing habitat complexity. Another expectation was that the number of juvenile fish (i.e. recruitment) would increase in rockpools where habitat complexity was increased, and that adults would make a greater contribution to assemblages in rockpools where habitat complexity was reduced.

\section{MATERIALS AND METHODS}

Study design. Our manipulation experiment was undertaken between 7 February and 7 August 2001 at 2 rocky headlands (Puckey's Bombora and Bass Point [34 35' S, $150^{\circ} 52^{\prime}$ E]) in southeastern New South Wales (NSW), Australia (Fig. 1). At each site 20 rockpools were studied; these were situated 50 to $200 \mathrm{~m}$ apart and were selected for similarity of physical variables, mainly volume (105 to 570 l), substratum type (pebbles, cobbles and small boulders) and tidal height (0.5 to $1.2 \mathrm{~m}$ above MLLW). Fishes were collected from the rockpools by hand after completely emptying the pools using a $12 \mathrm{~V}$ battery-powered submersible bilge pump of $9092 \mathrm{l} \mathrm{h}^{-1}$ capacity. A small hand net was also set over the end of the hose when rockpools were being emptied to capture any fish that were accidentally drawn into the pump. Following emptying, a thorough search of each pool was conducted, overturning all rocks and boulders and shaking foliose algae. The fishes collected were transferred to a 601 drum containing aerated seawater. They were identified and their total length (TL) measured to the nearest mm. Fork length (FL) was also measured for species of economic importance, e.g. Girella elevata. Fish were then re-

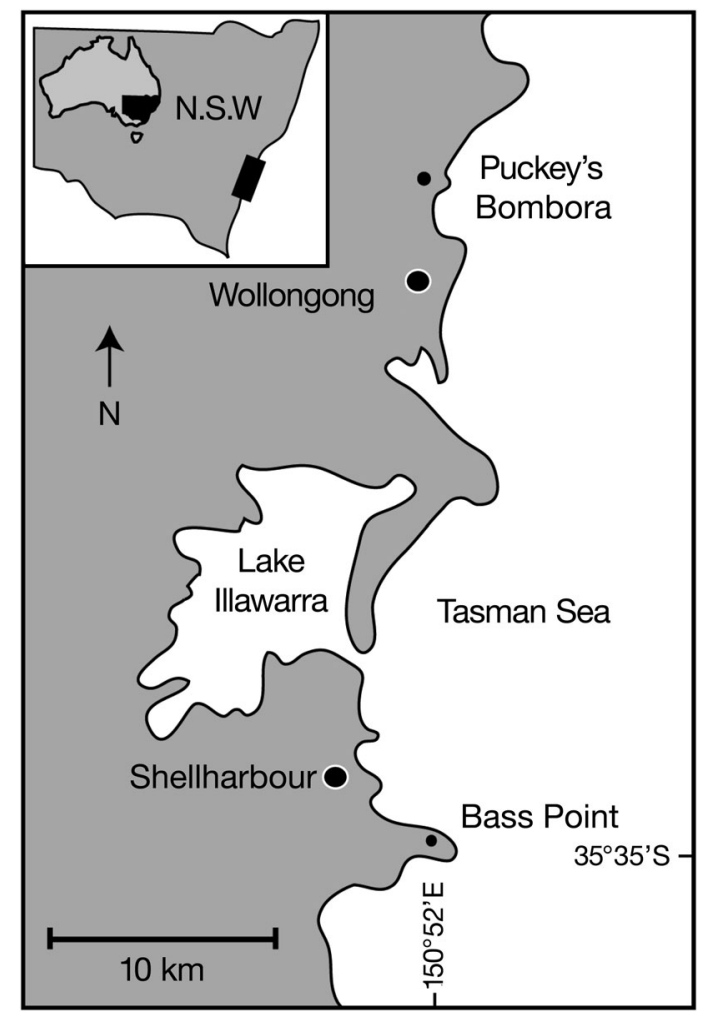

Fig. 1. Illawarra study region showing sampling locations at Puckey's Bombora and Bass Point in New South Wales (NSW), Australia 
leased alive into nearby rockpools or the shallow subtidal at least $10 \mathrm{~m}$ away from the pool being sampled, except if voucher specimens were retained for further identification. Rockpools were refilled using the bilge pump.

Before any manipulation of rockpool habitats was undertaken, each rockpool was sampled twice, separated by about $4 \mathrm{wk}$ to allow recolonisation of rockpools by fishes among samples (see Beckley 1985, Willis \& Roberts 1996, Griffiths 2003b, Griffiths et al. 2004). After fish were removed following the second sampling event, rockpool habitats were manipulated.

At each site rockpools were randomly allocated to 1 of 5 treatments, and each treatment was replicated using 4 pools at each site. The 5 treatments were as follows: (1) addition of algae and rocks (+R+A), (2) removal of all rocks and algae $(-\mathrm{R}-\mathrm{A}),(3)$ removal of all rocks but addition of algae $(-\mathrm{R}+\mathrm{A}),(4)$ addition of rocks but removal of all algae (+R-A), and (5) control pools (C), which were unmanipulated. The aim of the control pools was to determine if changes in fish assemblages in manipulated pools were due either to sampling disturbance or to natural temporal variation in fish assemblages, as is known to occur (see Griffiths 2003a). To ensure that control rockpools received the same disturbance as manipulated rockpools, all rocks and gravel were removed during sampling and returned after fish were removed. All rockpools were resampled on 2 occasions after manipulation at intervals of about 4 wk, which has been shown to be sufficient time for fish to recolonise rockpools (Beckley 1985, Griffiths 2002, Griffiths et al. 2004) and to recruit to artificial cover (Bell et al. 1987).

Since algae commonly found in rockpools could not be transplanted successfully between rockpools (see Silberschneider \& Booth 2001), algal cover was simulated in quantitative units by using artificial seagrass units (ASUs), which have been used extensively in estuaries (Bell 1985, Bell et al. 1985, Virnstein \& Curran 1986, Sogard 1989, Sogard \& Able 1994, Jenkins \& Sutherland 1997, Edgar 1999). The main objective of this procedure was not to physically mimic actual algae found in rockpools, but to introduce physical structure to the water column in a similar form. To further enforce the effect of structure alone, no epifauna was associated with the artificial algae. Eighteen lengths of blue nylon strapping (800 $\mathrm{mm}$ in length) were doubled around a $40 \times 40 \mathrm{~cm}$ square of reinforced steel mesh and secured with nylon cable ties to create shoot lengths of $400 \mathrm{~mm}$ and a density of 225 shoots $\mathrm{m}^{-2}$. This density was considered to be sufficient as it has been shown that fish settling from the plankton do not discriminate between artificial seagrass beds of different leaf densities, but recruit to any available shelter (Bell et al. 1987). The metal frame was secured in rockpools by fitting the frame with 2 metal saddles on opposite sides and securing them to $8 \mathrm{~mm}$ bolts, which were anchored into holes drilled in the rocky substratum.

After reviewing the results of the manipulation experiment, it was clear that substratum heterogeneity was an important factor but we observed few obvious trends involving treatments where algae were introduced. Therefore, additional experimentation was undertaken only using substratum heterogeneity. Treatments were reversed in rockpools that had rock cover initially added $(+\mathrm{R}-\mathrm{A}$ and $+\mathrm{R}+\mathrm{A})$ or removed $(-\mathrm{R}-\mathrm{A}$ and $-\mathrm{R}+\mathrm{A})$ in the first manipulation. The expectation was that after the second manipulation the numbers of fish and species would increase where rocks were added $(+\mathrm{R})$ and decrease where rocks were removed $(-\mathrm{R})$. Rockpools that received artificial algal treatments were included in this study by removing the artificial algae and reversing the rock cover treatments introduced in the first manipulation. This part of the experiment is herein termed 'Manipulation 2' and the overall experimental design is shown diagrammatically in Fig. 2.

Statistical analyses. Since the same rockpools were repeatedly sampled, a 3-factor repeated-measures ANOVA (RM-ANOVA) was used to test for significant differences in the mean numbers of species and individuals, and also the mean number of individuals representing the 4 most abundant species (standardised for rockpool volume), between sampling events (within-subjects factor with 6 levels), locations (amongsubjects factor with 2 levels) and treatments (amongsubjects factor with 5 levels). All factors were considered fixed. The assumption of sphericity of the variancecovariance matrix was tested using Mauchly's criterion and, if violated, F-tests were performed using Greenhouse-Geisser adjusted degrees of freedom. In cases where Mauchly's criterion was violated, the multivariate approach of performing RM-ANOVA was not undertaken as it is generally less powerful than the univariate approach (Nielson 2001). Student-Newman-Keuls (SNK) tests were used for a posteriori comparison among means for among-subjects factors, while within-subjects simple contrast tests were used to compare means for the within-subjects factor.

Non-metric multidimensional scaling (nMDS) was used to examine similarities in fish assemblage structure between locations, treatments and sampling events. Data were square-root transformed, to reduce the influence of highly abundant taxa, and a similarity matrix was constructed using the Bray-Curtis similarity coefficient (Clarke 1993). Analysis of similarities (ANOSIM) was used to test whether fish assemblages in a priori factorial groups differed statistically (Clarke 1993). Similarity percentages (SIMPER) were used to 


\section{Bass Point and Puckey's Bombora}

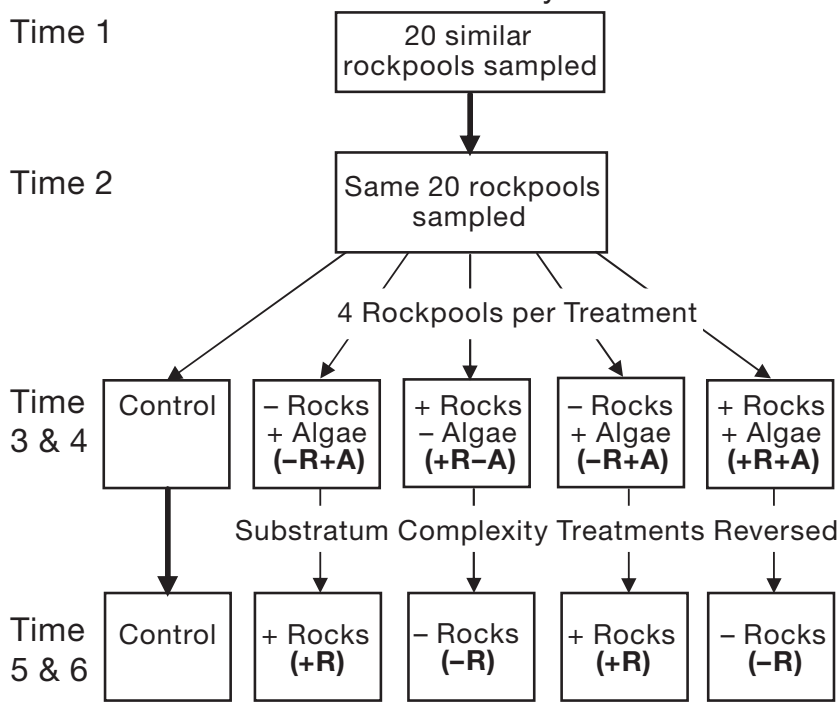

Fig. 2. Experimental design used to test influence of habitat heterogeneity on the structure of rockpool fish assemblages at Bass Point and Puckey's Bombora, NSW, Australia, after physically manipulating algal cover and substratum rock cover. Duration between sampling events ('Times') was around 4 wk. Treatment codes in bold

determine which species were responsible for differences in fish assemblages between selected groups. All multivariate analyses were carried out using the PRIMER (Plymouth routines in multivariate ecological research) package (version 5.2.2).

Length-frequency distributions were analysed to investigate whether habitat manipulations had an effect on the size composition of rockpool fish assemblages. Kolmogorov-Smirnov (K-S) 2-sample tests were used to determine whether length-frequency distributions of fish differed statistically after habitat manipulation for each treatment.

\section{RESULTS}

\section{Numbers of species and individuals}

A total of 1746 fish from 27 species were caught in rockpools during the study and their abundances at each location are shown in Table 1.

The significant Treatment $\times$ Time interaction and the highly significant differences for the Time factor for both numbers of species and individuals was the most important feature in the results of RM-ANOVAs (Fig. 2, Table 2). This indicated that differences in mean numbers of species and individuals were evident over time but were dependent upon the treatment examined. Although the patterns of variation in the
Table 1. Number of fish per species (in order of abundance) caught from 40 rockpools at Bass Point and Puckey's Bombora between 7 February and 7 August 2001. ${ }^{*}$ Species of economic importance

\begin{tabular}{|lccc|}
\hline Species & $\begin{array}{c}\text { Bass } \\
\text { Point }\end{array}$ & $\begin{array}{c}\text { Puckey's } \\
\text { Bombora }\end{array}$ & Total \\
\hline Bathygobius cocosensis & 555 & 189 & 744 \\
Enneapterygius rufopileus & 66 & 189 & 255 \\
Lepidoblennius haplodactylus & 8 & 171 & 179 \\
Heteroclinus fasciatus & 85 & 59 & 144 \\
Aspasmogaster costatus & 90 & - & 90 \\
Istiblennius edulentus & 54 & 12 & 66 \\
Girella elevata* & 55 & 7 & 62 \\
Heteroclinus whiteleggi & 46 & 14 & 60 \\
Parablennius intermedius & 17 & 19 & 36 \\
Istiblennius meleagris & 17 & 19 & 36 \\
Aspasmogaster liorhyncha & 1 & 20 & 21 \\
Abudefduf vaigiensis & 6 & 5 & 11 \\
Istiblennius edentulus & 10 & - & 10 \\
Ophiclinus gracilis & 8 & - & 8 \\
Myxus elongatus* & - & 4 & 4 \\
Tetractenos glaber & - & 4 & 4 \\
Acanthistius ocellatus & 3 & - & 3 \\
Gymnothorax prasinus & 3 & - & 3 \\
Filicampus tigris & 1 & 1 & 2 \\
Alabes dorsalis & 1 & - & 1 \\
Callogobius depressus & 1 & - & 1 \\
Chaetodontidae sp. & - & 1 & 1 \\
Epinephelus daemelii & 1 & - & 1 \\
Iso rhothophilus* & 1 & - & 1 \\
Microcanthus strigatus & 1 & - & 1 \\
Parma microlepis & 1 & - & 1 \\
Scorpaena cardinalis & 1 & - & 1 \\
Totals & $\mathbf{1 0 3 2}$ & $\mathbf{7 1 4}$ & $\mathbf{1 7 4 6}$ \\
\hline
\end{tabular}

numbers of species and individuals did not differ among locations, as indicated by a non-significant Location $\times$ Treatment $\times$ Time interaction term, data could not be pooled across locations due to the significant Location main effect (Table 2). This was due to higher numbers of species and individuals being captured at Puckey's Bombora (SNK test). However, Fig. 3 reveals nearly identical patterns in the variation of number of species and individuals for each treatment at both locations. Therefore, the patterns described henceforth will incorporate both locations. For ease of interpretation, variations in numbers of species and individuals were examined separately for each of the manipulations. For the first manipulation, samples from Times 1 and 2 ('before' samples) were compared with samples from Times 3 and 4 ('after' samples) (Fig. 2). For the second manipulation, samples from Times 3 and 4 ('after' samples) were compared with samples from Times 5 and 6 ('reverse' samples) (Fig. 2).

In the first set of manipulations the numbers of species and individuals were not significantly different in rockpools used for control, $-\mathrm{R}+\mathrm{A},+\mathrm{R}+\mathrm{A}$ and $+\mathrm{R}-\mathrm{A}$ treatments (Fig. 3; within-subjects simple contrast 
Table 2. Results of RM-ANOVAs testing for significant differences in no. of species and no. of ind. $\mathrm{m}^{-3}$ among locations (Bass Point and Puckey's Bombora), treatments $(+\mathrm{R}+\mathrm{A},-\mathrm{R}-\mathrm{A}$, $-\mathrm{R}+\mathrm{A},+\mathrm{R}-\mathrm{A}$, control; see 'Materials and methods' for full treatment descriptions) and time (6 sampling events). Both no. of species and individuals data were $\log _{10}(x+1)$ transformed before analysis, which removed heteroscedasticity in data. Mauchly's criterion for sphericity of variances was violated for several species ( $p<0.001)$, so analysis was performed using Greenhouse-Geisser adjusted degrees of freedom. $\mathrm{MS}=$ mean squares; ${ }^{*} \mathrm{p}<0.05 i^{* *} \mathrm{p}<0.01 ;{ }^{* * *} \mathrm{p}<0.001$

\begin{tabular}{|c|c|c|c|c|}
\hline \multirow[t]{2}{*}{ Source } & \multicolumn{2}{|c|}{ Number of species } & \multicolumn{2}{|c|}{ Number of individuals } \\
\hline & df & MS & & \\
\hline \multicolumn{5}{|l|}{ Among subjects } \\
\hline Location (L) & 1 & $4.65^{* *}$ & 1 & $2.04^{*}$ \\
\hline Treatment (R) & 4 & 0.49 & 4 & $0.87^{*}$ \\
\hline $\mathrm{L} \times \mathrm{R}$ & 4 & 0.50 & 4 & 0.33 \\
\hline Residual & 30 & 0.3630 & 0.32 & \\
\hline \multicolumn{5}{|l|}{ Within subjects } \\
\hline Time $(\mathrm{T})$ & 3.17 & $0.80^{* * *}$ & 2.97 & $1.99^{* * *}$ \\
\hline $\mathrm{L} \times \mathrm{T}$ & 3.17 & $0.24^{*}$ & 2.97 & $0.46^{* *}$ \\
\hline $\mathrm{R} \times \mathrm{T}$ & 12.68 & $0.32^{* * *}$ & 11.87 & $0.69^{* * *}$ \\
\hline $\mathrm{L} \times \mathrm{R} \times \mathrm{T}$ & 12.68 & 0.06 & 11.87 & 0.06 \\
\hline Residual & 95.09 & 0.06 & 89.06 & 0.11 \\
\hline Mauchly's $W$ & \multicolumn{2}{|c|}{$0.176^{* * *}$} & \multicolumn{2}{|c|}{$0.288^{* *}$} \\
\hline $\begin{array}{l}\text { Greenhouse- } \\
\text { Geisser Epsilo }\end{array}$ & \multicolumn{2}{|c|}{0.634} & \multicolumn{2}{|c|}{0.594} \\
\hline
\end{tabular}

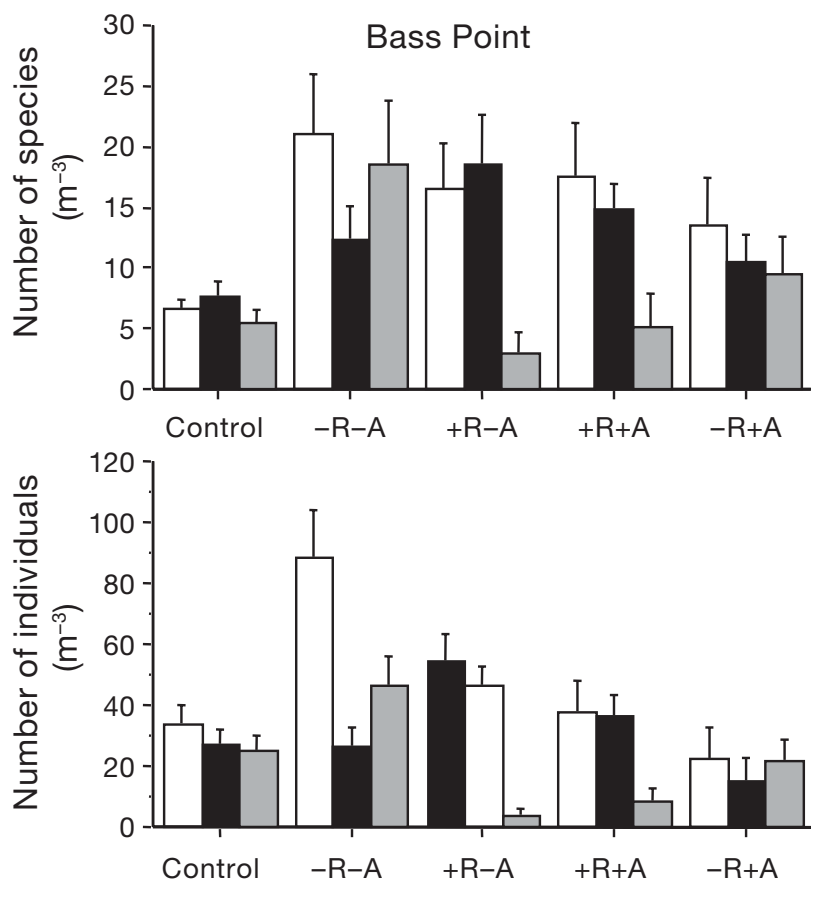

tests). However, both the number of species and individuals were significantly lower in the $-\mathrm{R}-\mathrm{A}$ treatment (Fig. 3; within-subjects simple contrast tests).

In the second manipulation experiment that only involved manipulation of substratum complexity, both the number of species and individuals were significantly lower in the treatments from which rocks had been removed (Fig. 3; within-subjects simple contrast tests). The effects of these manipulations were further reinforced by the fact that the number of species and individuals did not differ in the control rockpools after substratum complexity treatments were reversed in other rockpools ('After' vs. 'Reverse' samples) (Fig. 3).

\section{Variation in abundance of the most common species}

Repeated-measures ANOVAs revealed there were significant effects of manipulations upon the number of individuals representing the 4 most abundant species: the Treatment $\times$ Time interaction and the Time main effect were both significant for each species (Table 3). Because patterns of variation in the numbers of species and individuals were no different between Bass Point and Puckey's Bombora, as indicated by a non-significant Location $\times$ Treatment $\times$ Time inter-
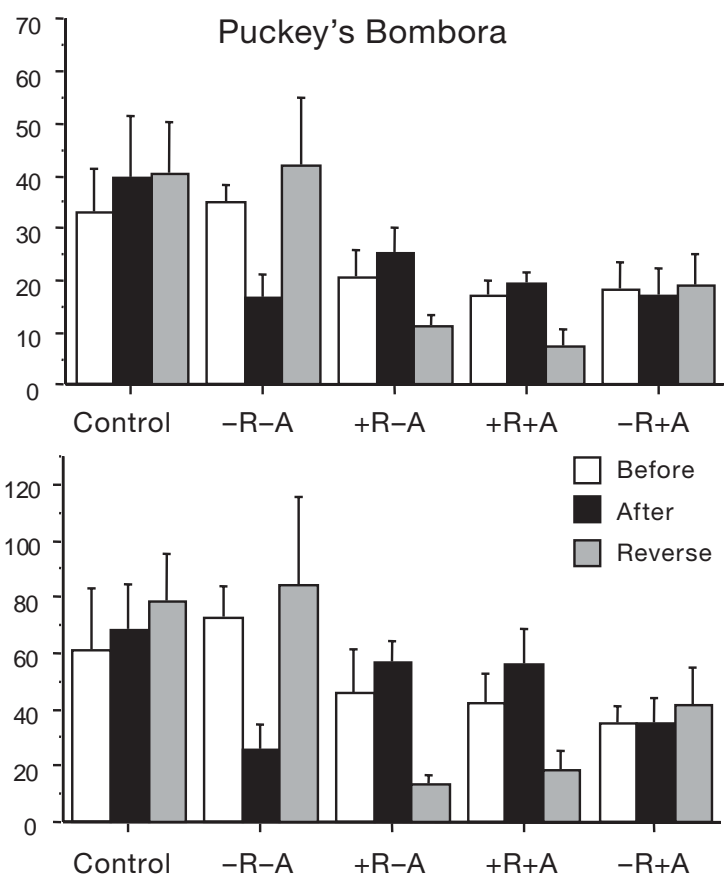

Treatment

Fig. 3. Mean $( \pm \mathrm{SE})$ no. of species and individuals caught before and after manipulation of water column and substratum complexity of rockpools at Bass Point and Puckey's Bombora, and after reversal of substratum complexity treatments only ('reverse'). Each before, after and reverse treatment consisted of replicate samples that were pooled from 2 sampling events. See 'Materials and methods' for complete descriptions of treatment codes 
action term (Table 3), data for each site were pooled and the variation in numbers of species and individuals for treatment over time examined in detail.

During the first set of manipulations, significant differences in the numbers of individuals were only evident in the $-\mathrm{R}-\mathrm{A}$ treatment (Fig. 4). The numbers of fish for 3 of the most abundant species were significantly lower after manipulation, with the exception of Lepidoblennius haplodactylus, which did not differ for any factor.

For the second manipulation, the number of Bathygobius cocosensis was significantly lower in the $-\mathrm{R}$ treatment but increased or did not differ in the $+\mathrm{R}$ treatment (Fig. 4). Similarly, the number of Enneapterygius rufopileus was significantly lower in the $-\mathrm{R}$ treatment, and also increased or did not differ in the $+\mathrm{R}$ treatment (Fig. 4). Lepidoblennius haplodactylus clearly showed significant increases in number in the $+R$ treatment, but also increased or did not differ in the $-\mathrm{R}$ treatment (Fig. 4). The number of Heteroclinus fasciatus dramatically decreased in both $-\mathrm{R}$ and $+\mathrm{R}$ treatments; however, this probably reflected a decrease in local abundance, as numbers in the control pools also declined after other pools were manipulated (Fig. 4).

\section{Fish assemblage structure: Manipulation 1}

Since ANOSIM revealed that the fish assemblages of Bass Point and Puckey's Bombora were significantly different $(R=0.220 ; \mathrm{p}=0.000)$, it was necessary to investigate the effects of experimental treatments separately for each site. Ordination of abundance data mainly revealed that differences in assemblage structure occurred after rocks and algae were removed at both locations (Fig. 5). However, ANOSIM revealed that fish assemblage structure differed in the $-\mathrm{R}-\mathrm{A}$ and $-\mathrm{R}+\mathrm{A}$ treatments. This was primarily due to lower abundances of Bathygobius cocosensis after manipulations in the $-\mathrm{R}-\mathrm{A}$ and $-\mathrm{R}+\mathrm{A}$ treatments, even though abundance of Istiblennius edentulus was higher before manipulation in the $-\mathrm{R}+\mathrm{A}$ treatment (Table 4a).

\section{Fish assemblage structure: Manipulation 2}

Ordination of abundance data revealed obvious differences in fish species composition with respect to treatments; however, separation of control rockpools, which were not manipulated, was also apparent (Fig. 6). ANOSIM revealed that $+\mathrm{R}$ and $-\mathrm{R}$ treatments and control rockpools produced significantly different fish assemblages after manipulations at both locations (Table 4b). Differences among the $+R$ treatment were due to higher abundances of resident benthic species after addition of rocks at Bass Point and Puckey's Bombora, even though Enneapterygius rufopileus was caught in higher numbers before manipulations at Puckey's Bombora (Table 4b). Differences among the $-\mathrm{R}$ treatment reflected similar results to the $+\mathrm{R}$ treatment in that benthic resident species had highest abundances at both locations when rock cover was present (Table $4 \mathrm{~b}$ ). It was interesting to note that removal of rocks also resulted in lower numbers of the mid-water dweller Girella elevata.

Table 3. Results of RM-ANOVAs testing for significant differences in no. of ind. $\mathrm{m}^{-3}$ for the 4 most abundant species among locations (Bass Point and Puckey's Bombora), treatments (+R+A, $-\mathrm{R}-\mathrm{A},-\mathrm{R}+\mathrm{A},+\mathrm{R}-\mathrm{A}$, control) and time (6 sampling events). Both no. of species and individuals were $\log _{10}(x+1)$ transformed before analysis, which removed heteroscedasticity in data. Mauchly's criterion for sphericity of variances was satisfied $(\mathrm{p}>0.05)$ in each case so analysis was performed using unadjusted degrees of freedom. Mean squares are shown; ${ }^{*} \mathrm{p}<0.05_{i}{ }^{* *} \mathrm{p}<0.01_{i}{ }^{* * *} \mathrm{p}<0.001$

\begin{tabular}{|c|c|c|c|c|c|c|c|c|}
\hline Source & df & $\begin{array}{l}\text { athygobius } \\
\text { cocosensis }\end{array}$ & df & $\begin{array}{l}\text { Enneapterygius } \\
\text { rufopileus }\end{array}$ & df 1 & $\begin{array}{l}\text { epidoblennius } \\
\text { laplodactylus }\end{array}$ & df & $\begin{array}{l}\text { Heteroclinus } \\
\text { fasciatus }\end{array}$ \\
\hline \multicolumn{9}{|l|}{ Among subjects } \\
\hline Location & 1 & $3.37^{* *}$ & 1 & $18.90^{* * *}$ & 1 & $14.63^{* * *}$ & 1 & 1.71 \\
\hline Treatment & 4 & $1.56^{*}$ & 4 & 0.73 & 4 & $1.31^{*}$ & 4 & $1.31^{*}$ \\
\hline Location $\times$ Treatment & 4 & 0.28 & 4 & 0.06 & 4 & $1.76^{* *}$ & 4 & 0.24 \\
\hline Residual & 30 & 0.43 & 30 & 0.36 & 30 & 0.35 & 30 & 0.47 \\
\hline \multicolumn{9}{|l|}{ Within subjects } \\
\hline Time & 3.20 & $1.92^{* * *}$ & 3.55 & $6.05^{* * *}$ & 3.14 & $7.63^{* * *}$ & 3.29 & $6.96^{* * *}$ \\
\hline Location $\times$ Time & 3.20 & $2.34^{* * *}$ & 3.55 & $0.62^{*}$ & 3.14 & $0.53^{* *}$ & 3.29 & 0.38 \\
\hline Treatment $\times$ Time & 12.79 & $0.74^{* * *}$ & 14.18 & $0.41^{*}$ & 12.55 & $0.41^{* * *}$ & 13.16 & $0.46^{*}$ \\
\hline Location $\times$ Treatment $\times$ Time & 12.79 & 0.19 & 14.18 & 0.23 & 12.55 & 0.13 & 13.16 & 0.29 \\
\hline Residual & 95.89 & 0.16 & 106.35 & 0.22 & 94.16 & 0.12 & 98.68 & 0.15 \\
\hline Mauchly's $W$ & \multicolumn{2}{|c|}{$0.041^{* * *}$} & \multicolumn{2}{|r|}{$0.052^{* * *}$} & \multicolumn{2}{|c|}{$0.055^{* * *}$} & \multicolumn{2}{|r|}{$0.066^{* * *}$} \\
\hline Greenhouse-Geisser Epsilon & \multicolumn{2}{|c|}{0.639} & \multicolumn{2}{|r|}{0.709} & \multicolumn{2}{|c|}{0.628} & \multicolumn{2}{|r|}{0.658} \\
\hline
\end{tabular}



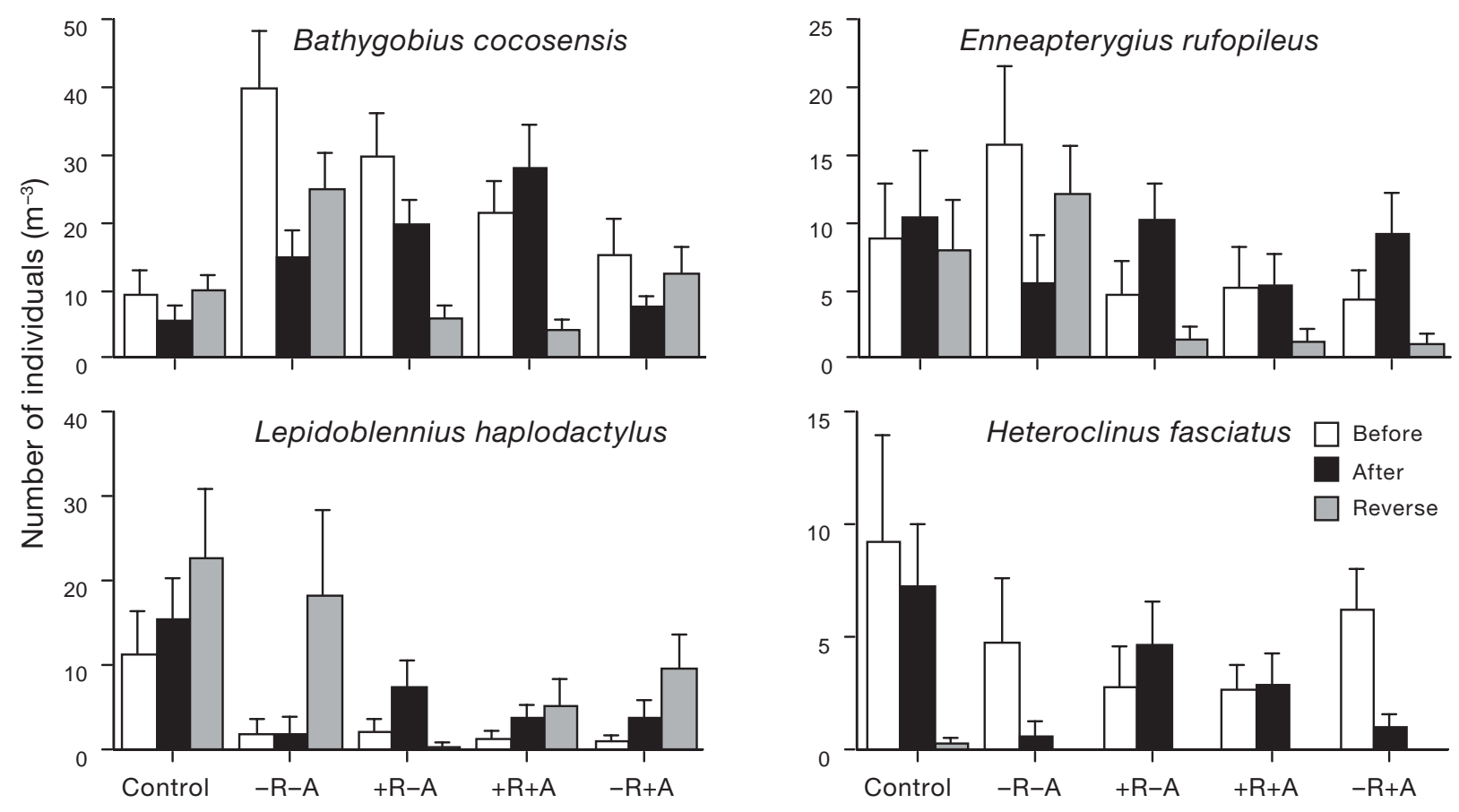

Treatment

Fig. 4. Mean $( \pm \mathrm{SE})$ no. of ind. representing 4 most abundant species before and after manipulation of water column and substratum complexity of rockpools, and following reversal of substratum complexity treatments only ('reverse'). Samples pooled for 2 locations; each bar comprises 8 samples averaged for 2 sampling events separated by 4 to 5 wk

The effects of $+R$ and $-R$ treatments were well supported by investigating the results of the control rockpools. Although significant differences among control rockpools were detected after manipulations were undertaken at the other rockpools, the species that were responsible for differences were not those contributing to at least $10 \%$ of the dissimilarity among samples, namely Aspasmogaster costatus and Heteroclinus fasciatus at Bass Point. Furthermore, the sampling events when some species were found in highest abundance in control pools did not show the same pattern of high abundance in treatment pools (Table 4b), which reinforced the treatment effects. There are 2 clear examples of the latter case. First, at Bass Point: Bathygobius cocosensis was in highest abundance in control pools before manipulations took place, whereas abundance was higher after manipulation for the $+\mathrm{R}$ treatment; second, at Puckey's Bombora: Lepidoblennius haplodactylus was more abundant in control pools after manipulations in other rockpools, but was more abundant before rocks were removed in the $-\mathrm{R}$ treatment (Table $4 \mathrm{~b}$ ).

\section{Length-frequency distributions}

There were no significant differences in lengthfrequency distributions for 2 of the most abundant spe- cies, Enneapterygius rufopileus and Heteroclinus fasciatus, after the first set of manipulations of rockpool habitats at Bass Point or Puckey's Bombora (Table 5). Although in numerous instances the absolute number of fish was lower before or after manipulations (depending upon the treatment administered), lengthfrequency distributions of fish in less abundant samples generally appeared to be a subset of those in samples where catches were higher (Fig. 7). Interestingly, length frequency distributions of these species significantly differed in control pools after manipulations took place in other rockpools (Table 5), with significantly fewer small $E$. rufopileus $(<20 \mathrm{~mm} \mathrm{TL})$ and large $H$. fasciatus (>40 mm TL) being recorded.

Length-frequency distributions of Bathygobius cocosensis and Lepidoblennius haplodactylus significantly differed after habitat manipulations (Table 5); however, this was likely to be a result of a recruitment event rather than an effect of habitat manipulation. For example, before manipulation of pools to which rocks were subsequently added, B. cocosensis was mainly represented by individuals $<30 \mathrm{~mm} \mathrm{TL}$; after manipulation (addition of rocks), the most abundant individuals were of 40 to $51 \mathrm{~mm}$ TL (Fig. 7e). However, length-frequency distributions of these species were also significantly different in control pools (Table 5), in that smaller fishes $(<25 \mathrm{~mm} \mathrm{TL})$ were more abundant 
Bass Point

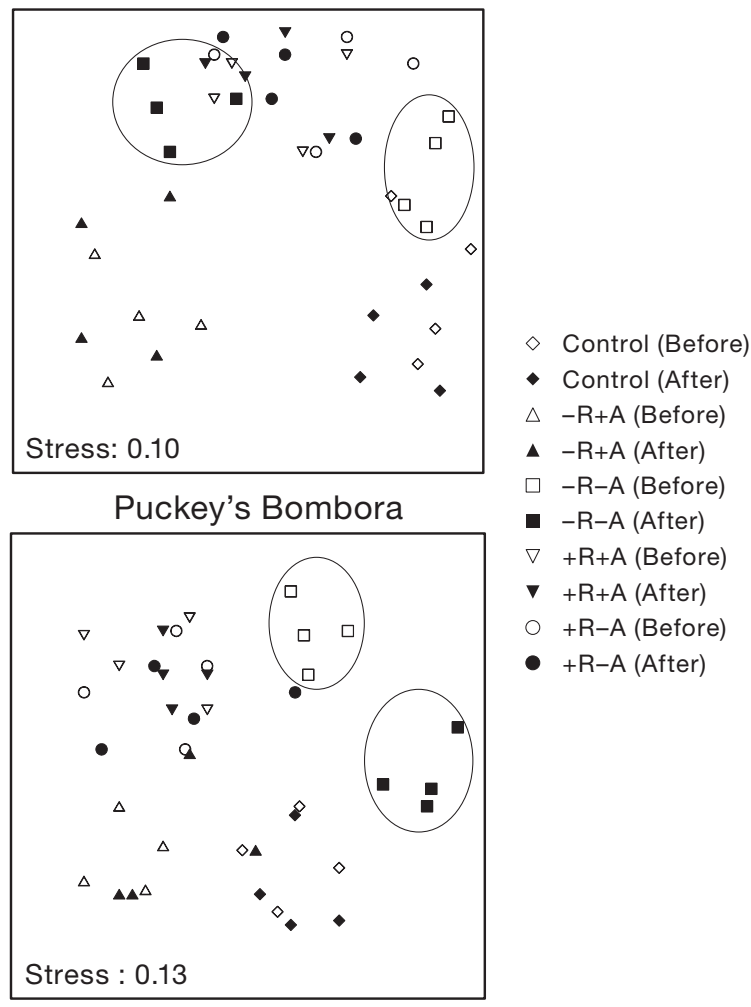

Fig. 5. Ordination plots (nMDS) of rockpool fish assemblages at Bass Point and Puckey's Bombora, before and after the first manipulations of rockpool habitats; 4 rockpools comprised each treatment at each location, and each rockpool was sampled twice before and after manipulation. Stress values are shown

before manipulations in pools receiving treatments, but that larger fishes ( 40 to $52 \mathrm{~mm} \mathrm{TL}$ ) were more abundant after manipulations (Fig. 7a).

Similarly, Lepidoblennius haplodactylus was mainly represented by individuals larger than $40 \mathrm{~mm}$ TL before manipulations in pools receiving any treatment, whereas after manipulations the most abundant individuals represented a single cohort $<30 \mathrm{~mm}$ TL (Fig. 7b-e). Again, control pools revealed a nearly identical pattern (Fig. 7a); thus, changes in size composition probably reflected variations across the entire intertidal population and were unlikely to be attributable to changes in habitat.

\section{DISCUSSION}

The results of the present study show that the species composition of rockpool ichthyofauna and the abundance of individual species is highly influenced by the physical structure of the substratum and suspended habitats in the water column, namely foliose

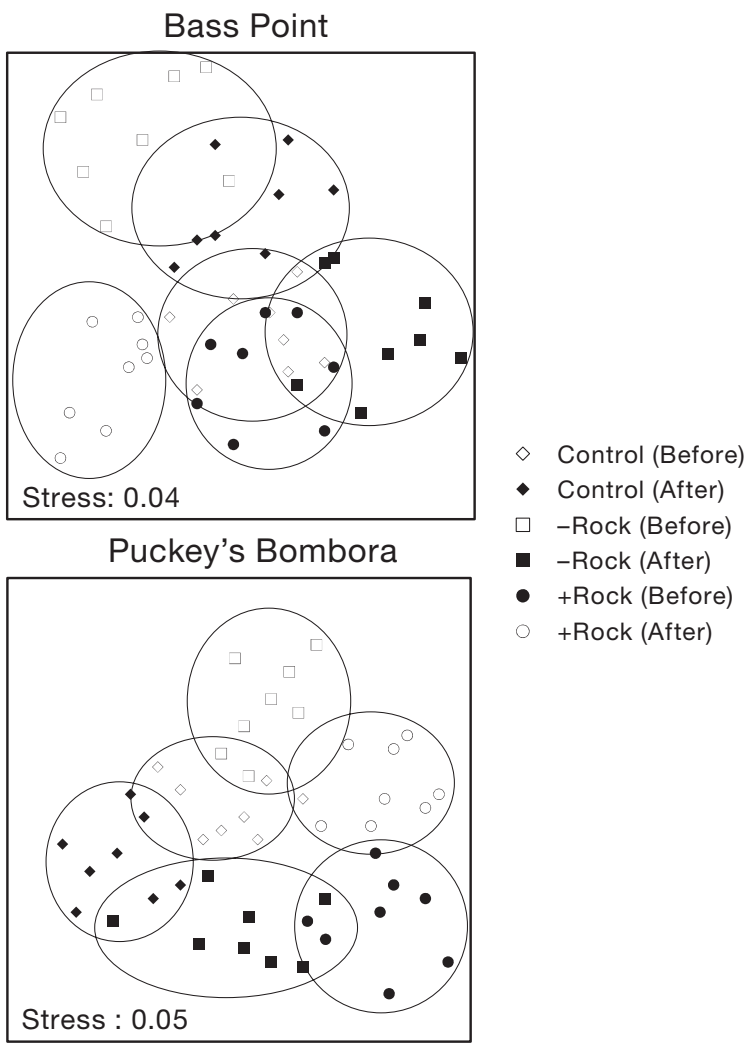

Fig. 6. Ordination plots (nMDS) of rockpool fish assemblages at Bass Point and Puckey's Bombora, before and after the second manipulations (substratum heterogeneity only); 8 rockpools comprised each treatment at each location, and each rockpool was sampled twice before and after manipulation. Stress values are shown

algae. However, the influences of these 2 habitats on rockpool fish assemblages do not appear to operate independently. Our results indicated that when one or both of these habitats was offered or increased in rockpools, the species composition and relative abundances and size composition of individual species were no different to those of the fish assemblages present before habitat manipulations took place. In contrast, the complete removal of both habitats was the only treatment that resulted in a significant change in the structure of fish assemblages, which was primarily a reduction in species richness and number of individuals. An explanation of our results may be that an increase in available habitat in rockpools is only important for fish to a point where other resources in rockpools, possibly food, may become limiting. Conversely, a decrease in available habitat may expose more fish to predation; thus, fewer fish may colonise rockpools with little available habitat. Herein we further discuss in detail the possible mechanisms in which fish assemblages may be structured by the 2 habitats manipulated in the present study. 
Table 4. Results of 1-way ANOSIM testing for differences in fish community structure after application of treatments to rockpools: (a) Manipulation 1 (Times 1 and 2 versus Times 3 and 4, Fig. 2), and (b) Manipulation 2 (Times 3 and 4 versus Times 5 and 6, Fig. 2). SIMPER analysis indicated species contributing at least $10 \%$ to dissimilarity among significantly different groups. Percentage contribution and whether abundances of individual species were higher before (B) or after (A) habitat manipulations shown in parentheses. Ac = Aspasmogaster costatus; $\mathrm{Al}=$ Aspasmogaster liorhyncha $; \mathrm{Bc}=$ Bathygobius cocosensis $; \mathrm{Er}=$ Enneaptery gius rufopileus; $\mathrm{Ge}=$ Girella elevata $; \mathrm{Hf}=$ Heteroclinus fasciatus; $\mathrm{Hw}=$ Heteroclinus whiteleggi; $\mathrm{Ie}=$ Istiblennius edentulus; $\mathrm{Lh}=$ Lepidoblennius haplodactylus; $\mathrm{Pi}=$ Parablennius intermedius $; \mathrm{Sl}=$ Scorpis lineolatus $;{ }^{*} \mathrm{p}<0.05 ;{ }^{* *} \mathrm{p}<0.01$;

$$
{ }^{* * *} \mathrm{p}<0.001
$$

\begin{tabular}{|c|c|c|c|c|}
\hline \multirow{2}{*}{$\begin{array}{l}\text { (a) } \\
\text { Treatment }\end{array}$} & \multicolumn{2}{|c|}{- Bass Point } & \multicolumn{2}{|c|}{ - Puckey's Bombora - } \\
\hline & $\mathrm{R}$ & SIMPER & $\mathrm{R}$ & SIMPER \\
\hline Control & 0.004 & - & 0.028 & - \\
\hline$+\mathrm{R}-\mathrm{A}$ & 0.053 & - & 0.085 & - \\
\hline$-\mathrm{R}-\mathrm{A}$ & $0.451^{* *}$ & $\begin{array}{c}\mathrm{Bc}(\mathrm{B}), \mathrm{Hf}(\mathrm{B}), \\
\mathrm{Ac}(\mathrm{B})\end{array}$ & 0.005 & - \\
\hline$-\mathrm{R}+\mathrm{A}$ & $0.355^{* *}$ & $\begin{array}{c}\mathrm{Bc}(\mathrm{B}), \mathrm{Ac}(\mathrm{B}), \\
\mathrm{Ie}(\mathrm{B})\end{array}$ & $0.300^{* *}$ & $\begin{array}{c}\operatorname{Er}(A), \operatorname{Hf}(B), \\
\text { Lh (B) }\end{array}$ \\
\hline \multirow[t]{2}{*}{$+\mathrm{R}+\mathrm{A}$} & 0.081 & - & 0.070 & - \\
\hline & \multicolumn{2}{|c|}{ Global $\mathrm{R}=0.216^{* * *}$} & \multicolumn{2}{|c|}{ Global $\mathrm{R}=0.189^{* * *}$} \\
\hline (b) & \multicolumn{2}{|c|}{ — Bass Point $ـ$} & \multicolumn{2}{|c|}{ - Puckey's Bombora - } \\
\hline Treatment & $\mathrm{R}$ & SIMPER & $\mathrm{R}$ & SIMPER \\
\hline Control & $0.499^{* *}$ & $\begin{array}{c}\text { Bc (B), Ac (B), } \\
\text { Hf (B) }\end{array}$ & $0.323^{* *}$ & $\begin{array}{c}\operatorname{Er}(\mathrm{B}), \operatorname{Lh}(\mathrm{A}), \\
\mathrm{BC}(\mathrm{A})\end{array}$ \\
\hline From $-\mathrm{R}$ to $+\mathrm{R}$ & $0.098^{*}$ & $\begin{array}{c}\mathrm{Bc}(\mathrm{A}), \operatorname{Er}(\mathrm{A}), \\
\operatorname{Im}(\mathrm{A})\end{array}$ & $0.167^{* *}$ & $\begin{array}{c}\operatorname{Lh}(\mathrm{A}), \operatorname{Er}(\mathrm{B}) \\
\mathrm{BC}(\mathrm{A})\end{array}$ \\
\hline \multirow[t]{2}{*}{ From $+\mathrm{R}$ to $-\mathrm{R}$} & $0.493^{* * *}$ & $\begin{array}{c}\text { Bc (B), Ie (B), } \\
\text { Ge (B) }\end{array}$ & $0.303^{* * *}$ & $\begin{array}{c}\text { Bc (B), Er (B), } \\
\text { Lh (B) }\end{array}$ \\
\hline & \multicolumn{2}{|c|}{ Global $\mathrm{R}=0.286^{* * *}$} & \multicolumn{2}{|c|}{ Global $\mathrm{R}=0.169^{* * *}$} \\
\hline
\end{tabular}

\section{Substratum heterogeneity}

Substratum heterogeneity was clearly the most significant factor that influenced fish assemblage structure, as the numbers of species and individuals decreased by removing rock cover. These findings are in agreement with the results of Davis (2000), who manipulated substratum heterogeneity in rockpools in the USA and found that more fish recolonised rockpools of high heterogeneity than rockpools with low heterogeneity. Our study revealed that an increase in rock cover (substratum heterogeneity) in rockpools where rock cover was already present did not necessarily increase the number of individuals or species, nor did it influence species composition. In contrast, the complete removal of rocks resulted in dramatic declines in species numbers and fish, which may have been due to the vast majority of taxa being benthic or at least demersal.
Thus, an increase in substratum heterogeneity would potentially increase the number of microhabitats available and result in higher numbers of fish being able to make use of a rockpool. In the first manipulation, increasing rock cover in a rockpool may not have had a dramatic effect on fish assemblage structure if its carrying capacity had already been reached due to limitation by some resources other than habitat availability. Addition of rock cover may increase the number of microhabitats available for additional fish to exploit; however, if other resources, such as food, are limited, then there may be little incentive for fish to remain in those rockpools. Alternatively, where rocks are completely removed there is no protection from predators and shelter becomes the limiting resource.

These findings are similar to those of Davis (2000) who found no increase in the number of species and individuals where rock cover was added to rockpools, but found a significant $(p<0.001)$ decrease in the number of species and individuals where rock cover was completely removed. However, her results appear to reflect largely the dependence on rock cover by the most abundant species found in her study pools (Clinocottus analis, Girella nigricans and Gobiesox rhessodon) and not necessarily the entire assemblage. In contrast, Cross (1981) arrived at the rigid conclusion that cover is not a limiting resource for fish in rockpools, after finding that fish numbers did not change when all cover was experimentally removed from rockpools at 3 localities in North America. However, he also suggests that a 25 to $69 \%$ decrease in water depth in rockpools that received additional rock cover may

Table 5. Results of Kolmogorov-Smirnov tests, testing for differences in lengthfrequency distributions of 4 most abundant species after application of treatments to rockpools. Z-values are shown; ${ }^{*} \mathrm{p}<0.05 ;{ }^{* *} \mathrm{p}<0.01 ;{ }^{* * *} \mathrm{p}<0.001$

\begin{tabular}{|lcccc|}
\hline Treatment & $\begin{array}{c}\text { Bathygobius } \\
\text { cocosensis }\end{array}$ & $\begin{array}{c}\text { Enneapterygius } \\
\text { rufopileus }\end{array}$ & $\begin{array}{c}\text { Lepidoblennius } \\
\text { haplodactylus }\end{array}$ & $\begin{array}{c}\text { Heteroclinus } \\
\text { fasciatus }\end{array}$ \\
\hline Control & $1.829^{* *}$ & $2.247^{* * *}$ & $1.903^{* * *}$ & $1.581^{*}$ \\
-R-A & 1.213 & 1.347 & $1.414^{*}$ & 1.201 \\
+R-A & $3.762^{* * *}$ & 1.204 & $1.610^{*}$ & 1.061 \\
+R+A & 1.078 & 1.322 & 1.095 & 0.690 \\
-R+A & 0.971 & 1.103 & 1.063 & 0.669 \\
\hline
\end{tabular}



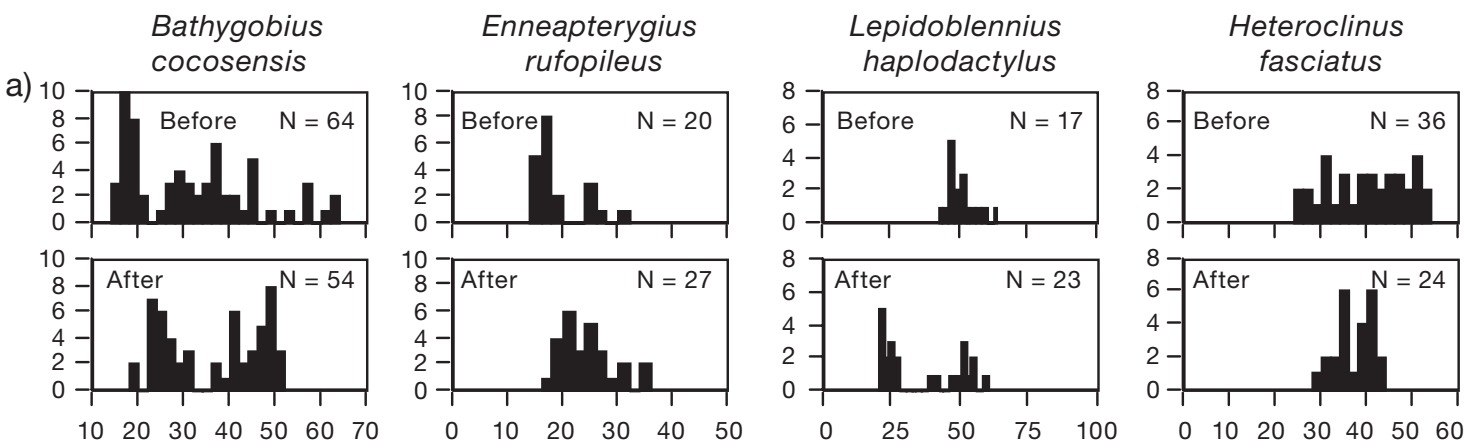

b) 10
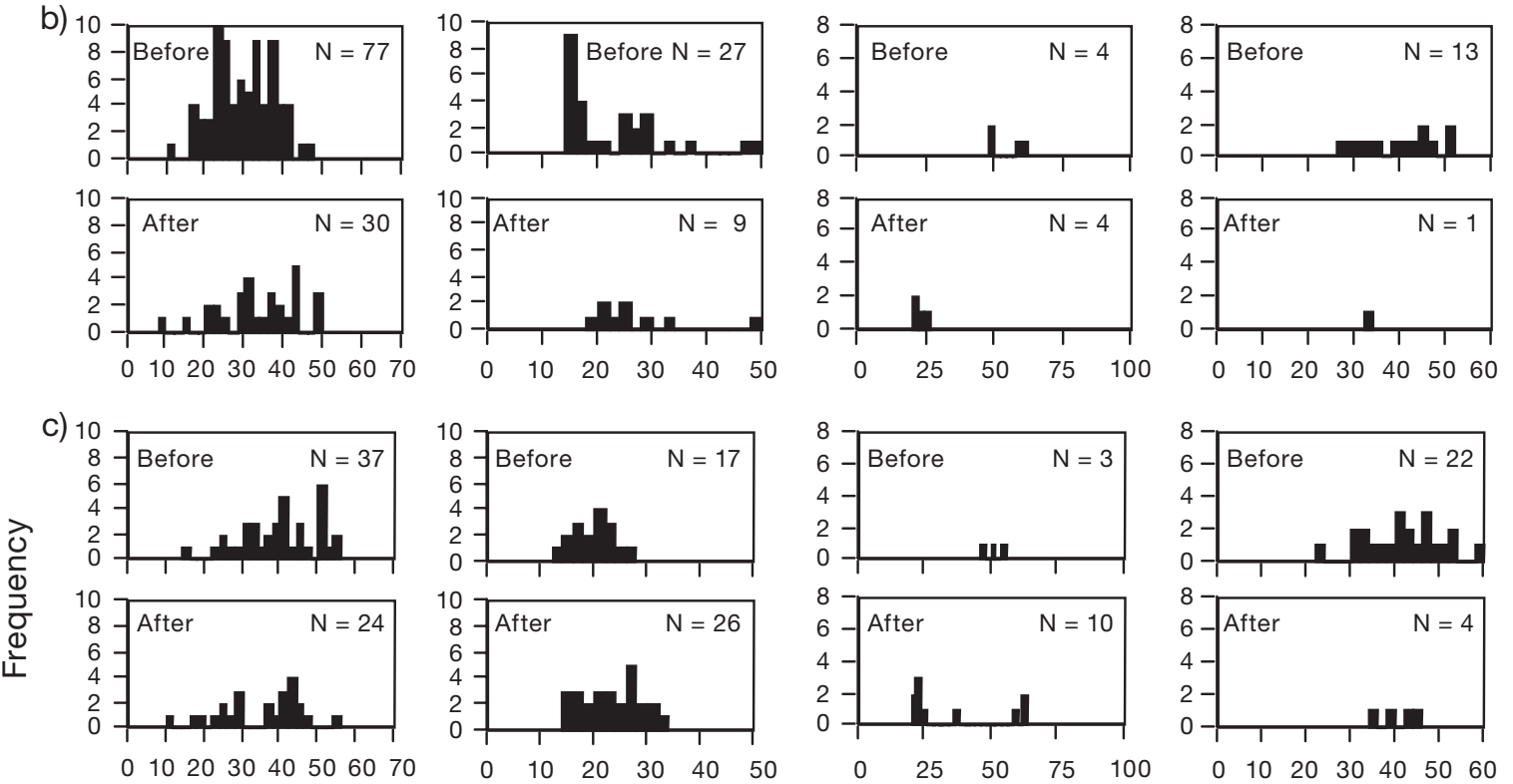

d) 15
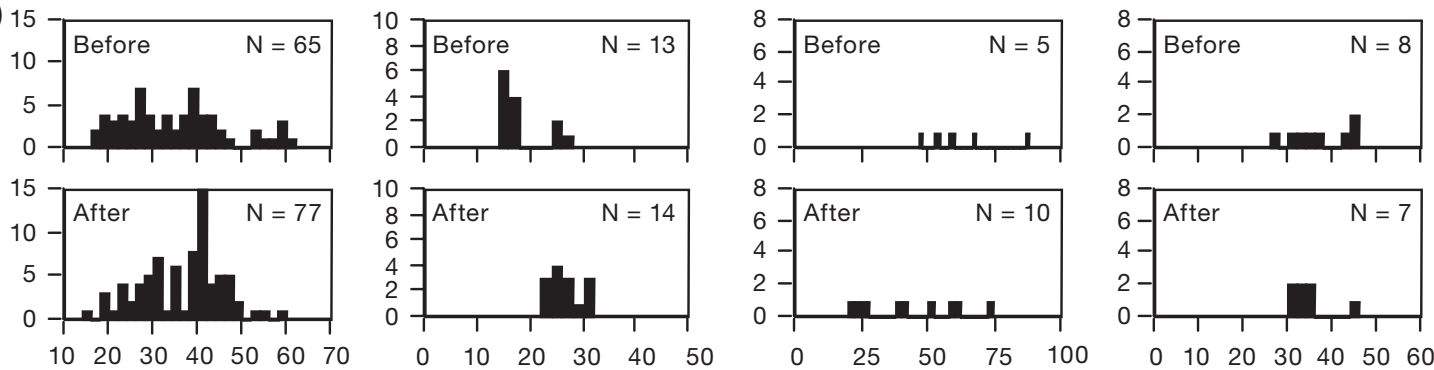

e) 15
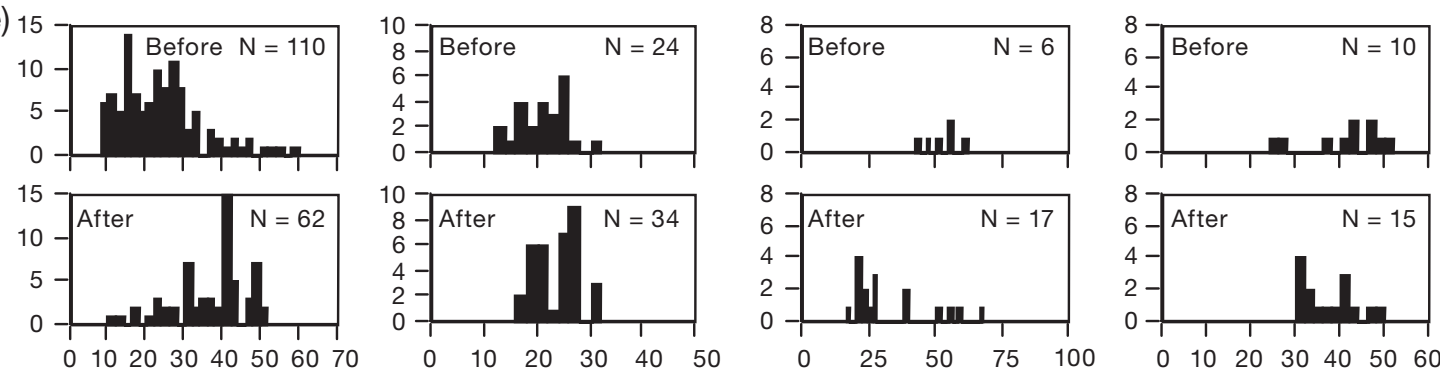

Total Length $(\mathrm{mm})$

Fig. 7. Length-frequency distributions of 4 most abundant species in rockpools (combined for Bass Point and Puckey's Bombora), before and after manipulation of rockpool complexity: (a) control (unmanipulated), (b) rocks and natural algal cover removed, (c) algae added and rocks removed, (d) algae and rocks added, and (e) rocks added and algae removed. 'Before' and 'after' data obtained from 2 sampling events, where 8 rockpools ( 4 at each location) were subjected to each treatment 
have confounded the results for numerous species (mainly from the families Cottidae, Stichaeidae and Pholidae) that prefer deeper rockpools.

Another possible explanation for our observation that numbers of species and individuals did not increase with increasing substratum complexity may be that fish display no preference for rockpool habitats for feeding. There is evidence to suggest that most fishes only occupy rockpools as temporary refuges before moving throughout the intertidal zone during high tide to feed (Bennett et al. 1983). For example, Marsh et al. (1978) found that clinids in South Africa travel throughout the intertidal zone to feed at high tide but become less active and seek cover among algal fronds in rockpools at low tide. This would certainly explain the lack of variation in fish assemblages where rock cover was added to existing rock cover, as there is probably already sufficient cover available for the short time fish intend using the rockpool. In rockpools where there is no cover, fish would obviously be at significantly greater risk of predation from terrestrial predators such as piscivorous birds (see Robertson 1974, Yoshiyama 1981, Gibson \& Yoshiyama 1999) and snakes (Batts 1961), and so they probably seek alternative refugia. However, it is noteworthy that on some occasions fish were seen - albeit in low numbers - in other rockpools (not sampled in this study) that had absolutely no algae or rock cover. This may indicate that some fish may accidentally become stranded by the receding tide and may resort to any available refuge.

Although substratum heterogeneity appeared to strongly influence rockpool fish assemblages, the combined effects of both substratum and suspended cover may also affect them. However, individual species certainly have the capacity to use either habitat type, at least in the short-term. For example, abundant species that are nearly exclusively benthic, such as Bathygobius cocosensis, Enneapterygius rufopileus and Lepidoblennius haplodactylus, were still found in high numbers in rockpools where only suspended algal cover was offered. Furthermore, the abundance of clinids is often closely related to the presence of algae (Marsh et al. 1978), but in the present study it appeared that the presence of both habitats was important for the most abundant clinid, Heteroclinus fasciatus. These combined effects of habitats were well illustrated at the assemblage level, particularly in the first manipulation study. Here, significantly lower numbers of species and individuals were found in rockpools where both rocks and natural algae cover was removed, whereas fish assemblage structure was maintained at pre-perturbation levels in other rockpools as long as at least 1 habitat type was offered.

\section{Suspended cover (ASUs)}

The present study showed that increasing structural heterogeneity in the water column does not necessarily increase fish abundance or species richness at Bass Point and Puckey's Bombora. This finding strongly counters the hypothesis that increased algal cover increases the number of species and fish in intertidal habitats (see Bennett \& Griffiths 1984, Davis 2000). These studies reached this conclusion on the basis of multiple regression analyses from mensurative studies, which are unable to define cause and effect (Underwood et al. 2000). Nevertheless, Bennett \& Griffiths (1984) suggested that the presence of algal cover may increase species richness and abundance of fish due to an increase in the number of microhabitats, but they could not conclude whether this was due to shelter or dietary preference of the fishes. In a study of algaldwelling clinids in South African rockpools, Marsh et al. (1978) found that the diets of most fish contained items that are not associated with algae, and thus feeding probably occurs elsewhere within the rockpool or adjacent intertidal zone.

The use of ASUs in the present study allowed the effects of suspended cover (apart from associated food sources) on rockpool fish assemblages to be isolated. Our conclusion that fish assemblage structure was no different after introduction of ASUs reveals 2 important findings. First, ASUs attract fish communities that are similar to those attracted by natural algae, and are therefore suitable for manipulation studies of this type. Second, cover alone in the water column has a significant influence on the fish assemblage structure of rockpools. This can be illustrated clearly when considering that the blue colour of the 'shoots' did not resemble any natural algae or sponges that many fishes appeared to use as shelter in the rockpools at the 2 sites studied. Many fishes are camouflaged against the generally dark brown and green algae in rockpools, so their stark contrast against the blue shoots may provide evidence that the artificial cover provides adequate refuge from predators and/or environmental conditions (wave surge and direct sunlight). The hypothesis that fishes reside in the experimental rockpools purely for the purpose of gaining shelter is further reinforced by the fact that, after removal of all natural algal cover and sponges, artificial shoots did not support any significant epiphytic cover to attract fishes by providing a significant food source.

Because this was apparently the first study to introduce artificial algal cover into rockpools, there are unfortunately few comparisons to be made with other studies. While Black \& Miller (1991) found that removal of intertidal weed cover had no effect on the abundance of fishes in Nova Scotia, comparisons with 
our study are further complicated because their catches mainly comprised subtidal species that only entered the intertidal to feed during high tide and were not permanent residents of this environment. Nevertheless, the results of the present study are in close agreement with those of Bell et al. (1985, 1987) who found that ASUs attracted fish assemblages similar to those observed in natural seagrass beds within temperate Australian estuaries. The absence of epiphytic biota associated with the artificial shoots used in these earlier studies provided sufficient evidence that cover alone is probably the most significant factor that attracts settling estuarine fishes. Bell et al. (1987) suggested that fish probably recruit to any available shelter, after they found that species common among seagrasses also recruited to other artificial structures such as man-made jetties and metal cages. This model also seems applicable to rockpools: fish consistently recruited to rockpools where ASUs were added even where there was no substratum cover.

Although Bell et al. (1987) were able to determine the role of seagrasses in the recruitment of postflexion and juvenile fishes, a large number of the fishes they examined only use seagrasses during their juvenile life phases (but see Bell \& Westoby 1986c). They gradually move to habitats that offer different food sources and less structural complexity. For example, yellowfin bream Acanthopagrus australis recruit to estuarine seagrass beds and remain there until they are a few months old and then move to bare substrata (Griffiths 2001). In contrast, rockpool ichthyofauna is primarily comprised of permanent residents that may use the same microhabitat type for their entire lives. In the present study, $80 \%$ of fish were greater than $30 \mathrm{~mm}$ TL and were thus not juveniles recruiting to the manipulated rockpools for the first time, but were relocating from adjacent rockpools. These results suggest that cover is still a significant factor for rockpool selection by adults, and that adults may be vulnerable to predation even at larger sizes during low tide when the rockpools become isolated and easily accessible to large terrestrial predators (e.g. piscivorous birds) (Gibson \& Yoshiyama 1999).

\section{CONCLUSION}

The rocky intertidal zone can be a highly structurally complex environment that supports a diverse suite of organisms. Rockpools are an obvious feature of the rocky intertidal zone, and the fishes that occupy these tidally isolated 'island' habitats face many natural and anthropogenic pressures. To cope with the natural pressures of the dynamic and often harsh intertidal environment and the possible threat of predation, rockpool fishes rely heavily upon the presence of physical structure within rockpools. Two major types of physical structure are (1) macrophytes that can provide shelter in an otherwise featureless water column, and (2) rocks covering the substratum, where interstitial spaces create refuges of varying sizes. Although some fish species may tend to prefer particular habitats within rockpools, e.g. the preference for algal fronds by clinids, this research has shown that most species found within rockpools are opportunistic and seek refuge in any available shelter.

Acknowledgements. We thank J. Butler and A. Griffiths for assistance with field work and installation of ASUs, and E. Hockey and J. Nicol for supplying tools and materials to undertake habitat manipulations. This paper is partly based upon research included in a $\mathrm{PhD}$ by S.P.G., funded by an Australian Postgraduate Award through the University of Wollongong. This paper represents contribution number 264 from the Ecology and Genetics Group at the University of Wollongong.

\section{LITERATURE CITED}

Angel A, Ojeda FP (2001) Structure and trophic organization of subtidal fish assemblages on the northern Chilean coast: the effect of habitat complexity. Mar Ecol Prog Ser 217:81-91

Batts BS (1961) Intertidal fishes as food of the common garter snake. Copeia 1961:350-351

Beckley LE (1985) Tide-pool fishes: recolonization after experimental elimination. J Exp Mar Biol Ecol 85:287-295

Bell JD (1985) The distributions of fish and decapods in seagrass beds. PhD thesis, Macquarie University, North Ryde

Bell JD, Westoby M (1986a) Importance of local changes in leaf height and density to fish and decopods associated with seagrasses. J Exp Mar Biol Ecol 104:249-274

Bell JD, Westoby M (1986b) Variation in seagrass height and density over a wide spatial scale: effects on common fish and decapods. J Exp Mar Biol Ecol 104:275-295

Bell JD, Westoby M (1986c) Abundance of macrofauna in dense seagrass is due to habitat preference, not predation. Oecologia 68:205-209

Bell JD, Steffe AS, Westoby M (1985) Artificial seagrass: how useful is it for field experiments on fish and macroinvertebrates? J Exp Mar Biol Ecol 90:171-177

Bell JD, Westoby M, Steffe AS (1987) Fish larvae settling in seagrass: do they discriminate between beds of different leaf density? J Exp Mar Biol Ecol 111:133-144

Bell JD, Steffe AS, Westoby M (1988) Location of seagrass beds in estuaries: effects on associated fish and decapods. J Exp Mar Biol Ecol 122:127-46

Bennett BA, Griffiths CL (1984) Factors affecting the distribution, abundance and diversity of rock-pool fishes on the Cape Peninsula, South Africa. S Afr J Zool 19:97-104

Bennett B, Griffiths C, Penrith ML (1983) The diets of littoral fish from the Cape Peninsula. S Afr J Zool 18:343-352

Black R, Miller RJ (1991) Use of the intertidal zone by fish in Nova Scotia. Environ Biol Fish 31:109-121

Caley MJ, St John J (1996) Refuge availability structures assemblages of coral reef fishes. J Anim Ecol 65:414-428 
Clarke KR (1993) Non-parametric multivariate analyses of changes in community structure. Aust J Ecol 18:117-143

Cross JN (1981) Structure of a rocky intertidal fish assemblage. PhD thesis, University of Washington

Davis JLD (2000) Spatial and seasonal patterns of habitat partitioning in a guild of southern California tidepool fishes. Mar Ecol Prog Ser 196:253-268

Edgar GJ (1999) Experimental analysis of structural versus trophic importance of seagrass beds. II. Effects on fishes, decapods and cephalopods. Life Environ 49:249-260

Friedlander AM, Parrish JD (1998) Habitat characteristics affecting fish assemblages on a Hawaiian coral reef. J Exp Mar Biol Ecol 224:1-30

Garcia-Charton JA, Perez-Ruzafa A (2001) Spatial pattern and the habitat structure of a Mediterranean rocky reef fish local assemblage. Mar Biol 138:917-934

Gause GF (1934) The struggle for existence. Hafner, New York

Gibson RN, Yoshiyama RM (1999) Intertidal fish communities. In: Horn MH, Martin KLM, Chotkowski MA (eds) Intertidal fishes: life in two worlds. Academic Press, San Diego, p 264-296

Griffiths SP (2001) Recruitment and growth of juvenile yellowfin bream, Acanthopagrus australis Günther (Sparidae), in an Australian intermittently open estuary. J Appl Ichthyol $17: 240-244$

Griffiths SP (2002) Structure and dynamics of intertidal rockpool fish assemblages in southeastern Australia. PhD thesis, University of Wollongong

Griffiths SP (2003a) Spatial and temporal dynamics of temperate Australian rockpool ichthyofaunas. Mar Freshw Res 54: 163-176

Griffiths SP (2003b) Homing behaviour of intertidal rockpool fishes in south-eastern New South Wales, Australia. Aust J Zool 51:387-398

Griffiths SP, West RJ, Davis AR, Russell KG (2004) Fish recolonization of temperate Australian rockpools: a quantitative experimental approach. Fish Bull 102:634-647

Grinnell J (1917) The niche relationships of the California thrasher. Auk 34:427-433

Hixon MA, Beets JP (1993) Predation, prey refuges and the structure of coral-reef fish assemblages. Ecol Monogr 63:77-101

Horn MH, Martin KLM, Chotkowski MA (1999) Introduction. Intertidal fish communities. In: Horn $\mathrm{MH}$, Martin KLM, Chotkowski MA (eds) Intertidal fishes: life in two worlds. Academic Press, San Diego, p 1-6

Huffaker CB (1958) Experimental studies on predation: dispersion factors and predator-prey oscillations. Hilgardia 27:343-383

Jenkins GP, Sutherland CR (1997) The influence of habitat

Editorial responsibility: Otto Kinne (Editor-in-Chief), Oldendorf/Luhe, Germany structure on nearshore fish assemblages in a southern Australian embayment: colonisation and turnover rate of fishes associated with artificial macrophyte beds of varying physical structure. J Exp Mar Biol Ecol 218:103-125

Jones GP, Syms C (1998) Disturbance, habitat structure and the ecology of fishes on coral reefs. Aust J Ecol 23:287-297

Kohn AJ (1967) Environmental complexity and species diversity in the gastropod genus Conus on Indo-west Pacific reef platforms. Am Nat 101:251-259

Laegdsgaard P, Johnson C (2001) Why do juvenile fish utilise mangrove habitats? J Exp Mar Biol Ecol 257:229-253

Marsh B, Crowe TM, Siegfried WW (1978) Species richness and abundance of Clinid fish (Teleostei: Clinidae) in intertidal rock pools. S Afr J Zool 13:283-291

Nielson KJ (2001) Bottom-up and top-down forces in tide pools: test of a food chain model in an intertidal community. Ecol Monogr 71:187-217

Robertson I (1974) The food of nesting double-crested and pelagic cormorants at Mandarte Island, British Columbia, with notes on feeding ecology. Condor 76:346-348

Safriel UN, Ben-Eliahu MN (1991) The influence of habitat structure and environmental stability on the species diversity of polychaetes in vermetid reefs. In: Bell SS, McCoy ED, Mushinsky HR (eds) Habitat structure: the physical arrangement of objects in space. Chapman \& Hall, New York, p 349-369

Silberschneider V, Booth DJ (2001) Resource use by Enneapterygius rufopileus and other rockpool fishes. Environ Biol Fish 61:195-204

Sogard SM (1989) Colonization of artificial seagrass by fishes and decapod crustaceans-importance of proximity to natural eelgrass. J Exp Mar Biol Ecol 133:15-37

Sogard SM, Able KW (1994) Diel variation in immigration of fishes and decapod crustaceans to artificial seagrass habitat. Estuaries 17:622-630

Steele MA (1999) Effects of shelter and predators on reef fishes. J Exp Mar Biol Ecol 233:65-79

Underwood AJ, Chapman MG, Connell SD (2000) Observations in ecology: you can't make progress on processes without understanding the patterns. J Exp Mar Biol Ecol 250:97-115

Virnstein RW, Curran MC (1986) Colonization of artificial seagrass versus time and distance from source. Mar Ecol Prog Ser 29:279-288

Willis TJ, Roberts CD (1996) Recolonisation and recruitment of fishes to intertidal rockpools at Wellington, New Zealand. Environ Biol Fish 47:329-343

Yoshiyama RM (1981) Distribution and abundance patterns of rocky intertidal fishes in central California. Environ Biol Fish 6:315-332

Submitted: September 21, 2004; Accepted: November 29, 2005 Proofs received from author(s): April 3, 2006 